\title{
PERENCANAAN LAYOUT DATA CENTER DINAS KOMUNIKASI INFORMATIKA PERSANDIAN DAN STATISTIK PROVINSI KALIMANTAN TENGAH
}

\section{Data Center Layout Planning Department of Communication Informatics Code and Statistics of Central Kalimantan Province}

\author{
Abdul Hadi', Herkules ${ }^{2}$, Norhayati ${ }^{3}$ \\ 1,2) Program Studi Teknik Informatika, STMIK Palangka Raya \\ $\left.{ }^{3}\right)$ Program Studi Sistem Informasi, STMIK Palangka Raya \\ J.. G. Obos No. I I 4 Palangka Raya, Kalimantan Tengah \\ Email: 'abdulhadi@stmikplk.ac.di, ${ }^{2}$ herkules@stmikplk.ac.id, ${ }^{3}$ inoynorhayati@gmail.com
}

\begin{abstract}
ABSTRAK
Seiring berjalannya waktu teknologi informasi semakin berkembang pesat menyesuaikan kebutuhan publik dan perkembangan teknologi perangkat keras dan lunak, hal ini berimbas pada bertambahnya perangkat pengolahan dan penyimpanan data sehingga harus dipikirkan penempatan perangkat keras tersebut dalam sebuah data center untuk mempermudah proses maintenance dan monitoring kedepannya. Data center yang baik harus memenuhi standar yang telah ditetapkan, salah satunya adalah standarisasi TIA-942 yang dibuat oleh Telecommunications Industry Association (TIA). Penelitian ini melakukan perencanaan layout data center di Dinas Komunikasi Informatika Persandian dan Statistik (Diskominfo) Provinsi Kalimantan Tengah dengan menggunakan metode Prepare, Plan, Design, Implement, Operate, and Optimize (PPDIOO) yang merupakan salah satu dari metode network lifecycle untuk pengembangan infrastuktur data center dengan tahapan persiapan, perencanaan, desain, implementasi, operasi, dan optimalisasi. Tahapan metode yang digunakan pada penelitian ini dibatasi mulai dari tahapan persiapan, perencanaan dan desain dengan mengikuti standar TIA-942 basic Tier I berupa analisis kebutuhan perangkat keras dan lunak, penentuan lokasi dan ruangan data center, desain raised floor, desain sistem pendinginan, desain sistem kelistrikan, desain struktur kabel, desain rack dan kabinet, desain cable tray listrik dan data, desain proteksi kebakaran, desain sistem monitoring lingkungan, desian sistem pengamanan.
\end{abstract}

Kata kunci: Desain, Ruang Server, PPDIOO, Tier I, TIA-942

\begin{abstract}
As time goes by, information technology is growing rapidly according to public needs and developments in hardware and software technology, this has an impact on increasing data processing and storage devices, so it must be considered the placement of this hardware in a data center to simplify the maintenance and monitoring process going forward. A good data center must meet predetermined standards, one of which is the TIA-942 standard made by the Telecommunications Industry Association (TIA). This study conducted a data center layout planning at the Office of Communication Informatics Encryption and Statistics (Diskominfo) Central Kalimantan Province using the Prepare, Plan, Design, Implement, Operate, and Optimize (PPDIOO) method which is one of the network lifecycle methods for developing data center infrastructure with stages preparation, planning, design, implementation, operation, and optimization. The stages of the method used in this study are limited to the preparation, planning and design stages by following the basic Tier I TIA-942 standards in the form of hardware and software requirements analysis, determination of data center location and space, raised floor design, cooling system design, system design. electricity, cable structure design, rack and cabinet design, electric and data cable tray design, fire protection design, environmental monitoring system design, security system design.
\end{abstract}

Keywords: Design, Server Room, PPDIOO, Tier I, TIA-942

\section{Pendahuluan}

Teknologi informasi dalam pemerintahan (e-government) dapat membantu peningkatan dari segi efisiensi, transparansi, efektifitas, dan akuntabilitas sehingga pemerintahan tersebut dapat melayani publik dengan baik, cepat, dan efisien.

E-Government adalah pengembangan kinerja pelayanan pemerintahan berbasis digital untuk meningkatkan layanan publik agar dapat diakses kapanpun dan dimanapun. E-government meningkatkan hubungan lintas sektor antara masyarakat dan pemerintahan, antara pelaku bisnis dan pemerintahan, dan antar pemerintahan itu sendiri yaitu antar level legislatif, yudikatif, dan eksekutif. E-government juga mengeliminasi pengambilan keputusan berbasis hirarki kewenangan 
sehingga memperpendek jalur birokrasi, dan menyederhanakan akses layanan.

Penerapan e-government membutuhkan infrastruktur fisik yang baik berupa data center beserta sarana pendukung lainnya. Data center menjadi pusat data bagi pemerintah Provinsi Kalimantan Tengah (Prov. Kalteng). Desain perencanaan pembangunan data center sebagai fasilitas penempatan infrastuktur IT harus memperhatikan efisiensi alokasi ruang, penggunaan listrik, dan sistem mekanis yang lain.

Target pengembangan infrastruktur TIK pada data center Prov. Kalteng adalah konsolidasi data center, pemanfaatan data center seluruh SKPD di lingkungan Prov. Kalteng dapat disentralisasi dan dikelola secara terpadu, sehingga memberi manfaat lebih seperti penghematan belanja TIK dan memudahkan pengelolaan dan pengendalian permasalahan.

Untuk mewujudkan tujuan diatas diperlukan perencanaan dan kajian penempatan dan desain data center yang optimal untuk jangka panjang. Meskipun realisasinya pembangunan infrastuktur tersebut dibangun secara bertahap sesuai anggaran yang diperlukan hasilnya akan terencana sesuai master plan yang telah dibuat.

\section{Metode}

Metode yang digunakan pada penelitian ini menggunakan Prepare Plan Design Implement Operate and Optimize (PPDIOO). Metode PPDIOO dijadikan pendekatan awal dan akhir hingga proses pengembangan sesuai siklus perencanaan (Ismail and Ridwan, 2018). Terdapat enam tahapan utama yaitu :

I. Tahap persiapan

Tahapan ini berisi tentang studi literatur dan tinjauan lapangan untuk menetapkan analisis kebutuhan organisasi (requirment), strategi ekspansi infrastruktur, dan usulan konsep desain arsitektur.

2. Tahap perencanaan

Perencanaan yang dibuat diidentifikasi sesuai tujuan dan kebutuhan pengguna. Tahapan ini juga dianalisa kembali infrastruktur yang telah ada, sehingga hasil analisa tersebut dijadikan dasar perancangan desain data center.

3. Tahapan desain

Perancangan infrastruktur yang diusulkan berdasar standar TIA-942 Tier I.

4. Tahap implementasi

Penerapan dari tahapan perencanaan yang telah dibuat sebelumnya dengan menyesuaikan analisis yang sudah dilakukan. Pada tahapan ini juga dibuat ujicoba untuk memastikan sistem telah siap untuk diterapkan sesuai fungsinya.

5. Tahap operasi

Implementasi yang sudah dibuat dijalankan sesuai prosedur secara langsung.
6. Tahap optimasi

Setelah sitem beroperasi diperlukan evaluasi dari pihak yang ditunjuk sesuai bidangnya untuk mengidentifikasi masalah baru dan optimalisasi dari infrastuktur yang sudah ada sehingga meminimalisir terjadinya kerusakan dan masalah baru yang terjadi dikemudian hari.

Berdasarkan perencanaan data center diatas, penggunaan metode PPDIOO pada penelitian ini dibatasi pada pendekatan persiapan, perencanaan, dan desain.

\section{Hasil Dan Pembahasan}

Berdasarkan dokumen master plan TIK dan E-Gov Prov. Kalteng, target pengembangan infrastruktur TIK pada data center Prov. Kalteng adalah konsolidasi data center. Pengembangan data center Prov. Kalteng dirancang dengan optimalisasi virtualisasi dan storage area network (SAN) yang memadai. Pendekatan yang dilakukan dengan menggunakan standarisasi TIA-942 yakni pendekatan perencanaan data center Tier I yang dikeluarkan oleh Telecommunications Industry Association (TIA) yang bekerjasama dengan Asosiasi Industri Elektronika (EIA) (Dewandaru and Bachtiar, 20I4).

\section{Analisis Kebutuhan Perangkat keras}

Berdasarkan kebutuhan aplikasi e-government pada data primer master plan e-government tahun 2018 ada beberapa aplikasi yang harus berjalan pada sebuah server yaitu :

I. SIM PISDA

2. SIM Portal Kalteng Mobile

3. SIM PPID

4. SIM Kalteng Multimedia Storage \& Kalteng SMS Gateway

5. Sim Dashboard dan Ringkasan Informasi

6. Aplikasi Pengelolaan dan Monitoring Proyek

Untuk mendukung berjalannya sistem informasi $E$ Government Prov. Kalteng maka dibutuhkan beberapa komponen minimal perangkat keras seperti Tabel I.

Tabel I. Kebutuhan Minimal Perangkat Keras

\begin{tabular}{|c|c|}
\hline Perangkat Keras & Spesifikasi \\
\hline ProLiant DL380G9-684 & Dual Xeon E5- \\
\hline & $\begin{array}{l}\text { 2650v4, } 32 \mathrm{~GB}, \\
\text { 300GB SAS }\end{array}$ \\
\hline HP Server Memory & I6GB PC-2400 \\
\hline HP Server HDD & I.8TB SAS \\
\hline APC Rack LCD Consoles & $\begin{array}{l}8 \text { Port, VGA, } \\
\text { Rackmount }\end{array}$ \\
\hline $\begin{array}{l}\text { Routerboard CCRI072-IG- } \\
8 \mathrm{~S}+\end{array}$ & $\begin{array}{l}\text { NAND I28MB, } \\
\text { RAM } 16 \mathrm{~GB} \text {, SFP } 8 \\
\text { Port }\end{array}$ \\
\hline $\begin{array}{l}\text { HP Switch Managed 1920- } \\
\text { 24G }\end{array}$ & 24 Port, Manageable \\
\hline
\end{tabular}


Informatika Persandian dan Statistik Provinsi Kalimantan Tengah

Forinet Fortigate 90D $400 \mathrm{~V}$

APC Metered Rack PDU

APC 42U Server Racks Stabilizer YORITSU Digital 20KVA

Sistem Pendingin (AC) 5 PK Standing

AMP 24 Port Modular Patch $6 \mathrm{SL}$

Panels with Labels

\section{Analisis Kebutuhan Perangkat Lunak}

Pengembangan data center Prov. Kalteng dibuat dengan mengoptimalkan virtualisasi dan perangkat lunak lain berbasis open source. Berikut Tabel 2 kebutuhan perangkat lunak data center.

Tabel 2. Kebutuhan Perangkat Lunak Data Center

\begin{tabular}{lll}
\hline Nama Software & Versi & Keterangan \\
\hline Proxmox Ve & 5.2 & Os virtuliasasi \\
Debian & 9.4 & Os guest virtual \\
Apache2 for debian & 2.4 & Web server \\
Mysql & 8.0 & Database server \\
Bind & 9.12 .1 & DNS Server \\
Munin & 2.0 .37 & Resource watcher \\
Monit & 3.7 .1 & Service watcher \\
The dude & 2.1 & Network Monitor \\
Router OS & 6.33 & Router OS Mikrotik \\
\hline
\end{tabular}

Requirement minimum yang harus terpenuhi dalam perancangan infrastrukur data center dengan menggunakan standar TIA-942 adalah penentuan lokasi, sistem raised floor, sistem pendinginan, sistem kelistrikkan, struktur kabel, desain rack dan kabinet, desain cable tray listrik dan data, sistem proteksi kebakaran, sistem monitoring lingkungan dan sistem pengamanan.

\section{Penentuan Lokasi dan Ruangan Data Center}

Hal yang perlu diperhatikan dalam penentuan lokasi data center adalah lokasi yang dipilih bersifat expandable. Seiring berjalannya waktu perangkat keras akan selalu bertambah menyesuaikan kebutuhan kedepan, oleh karena itu penentuan lokasi menjadi sangat penting untuk antisipasi kebutuhan infrastuktur yang selalu meningkat. Salah satu standar TIA-942 mensyaratkan lokasi data center bebas gangguan atau interferensi dari gelombang elektromagnetis yang dapat mengurangi kinerja transfer rate data.

Lokasi perencanaan Ruang data center Diskominfo berada pada lantai dua gedung smart province, command center dan data center Jln. Tjilik Riwut KM 3 Palangka Raya dengan ukuran ruangan $54,25 \mathrm{~m}^{2}$. Ukuran ruangan tersebut cukup untuk pengembangan data center Prov. Kalteng dalam jangka panjang dan lokasi tersebut jauh dari gangguan interferensi elektromaknetis, sedangkan ruangan kontrol berada di depan ruangan server. Sehingga mudah dalam proses maintenance. Berikut Gambar I layout lantai dua gedung smart province, command center and data center Diskominfo Prov. Kalteng.

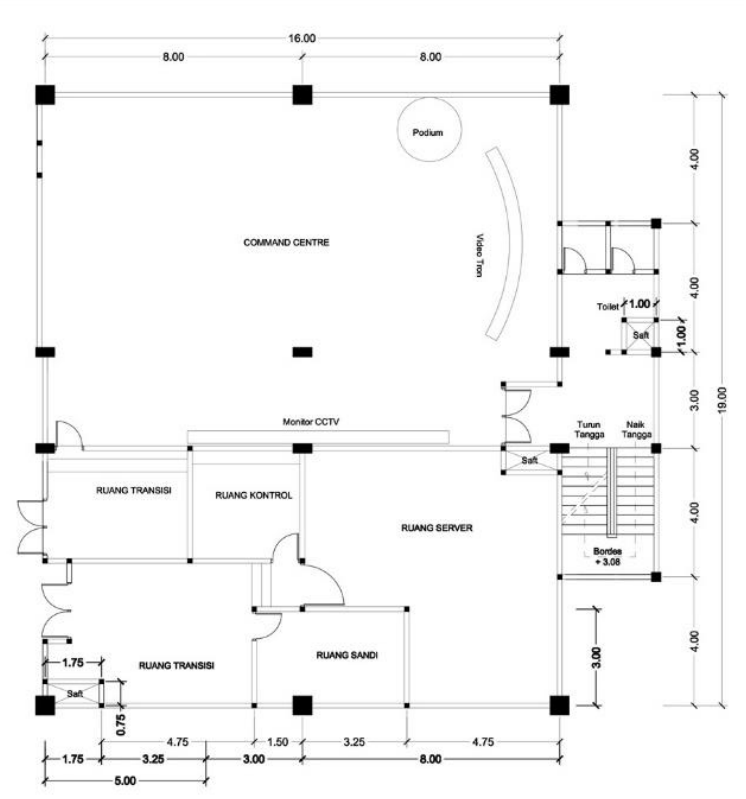

Gambar I. Layout lantai dua gedung Diskominfo

Pada Gambar I layout gedung ruangan yang akan dijadikan ruang data center mengikuti layout standar data center yang dikeluarkan oleh TIA 942 (Diminico, 2004).

Layout data center memiliki 5 ruangan yaitu :

I) Ruang transisi berfungsi untuk penerimaan semua equipment yang baru datang di data center.

2) Ruang komunikasi (control) berguna untuk ruang kerja administrator dan monitoring seluruh perangkat yang ada di data center.

3) Ruang comand center sebagai ruangan yang digunakan untuk konfrensi dan meeting room.

4) Ruang utama (server) tempat peletakan infrastuktur IT data center berupa perangkat keras seperti server, rack server, switch, router, firewall, storage dan lain-lain.

5) Ruang gudang tempat menyimpan peralatan suku cadang dan peralatan perangkat data center. 


\section{Desain Raised Floor}

Raised floor yang digunakan adalah jenis pedestal tiang penyangga berbahan galvanis dengan tinggi $30 \mathrm{~cm}$, menggunakan bolted stringer understructure (frame penyangga) berbahan galvanis serta dilengkapi oleh screws sebagai sekrup untuk pengunci dan panelnya memiliki ukuran panjang, lebar dan tinggi yaitu $60 \times 60 \times 3,5 \mathrm{~cm}$ berbahan Calcium Sulphate Panel Raised Floor yang telah dilapisi bahan vinyl anti statis atau lebih dikenal dengan nama raised floor tipe HPL (High Pressure Laminated).

Sesuai kriteria Tier I TIA-942 yang harus diperhatikan adalah ketentuan pemotongan lantai ubin. Pemotongan lantai ubin untuk vertical cabling pada kabinet harus ditempatkan dibawah kabinet atau lokasi lain agar terhindar dari bahaya tersandung dan dipasangi peredam grommet untuk meminimalkan hilangnya udara dingin melalui lubang diubin lantai (Rasmussen, 2014), berikut Gambar 2 denah pemasangan raised floor pada ruangan server.

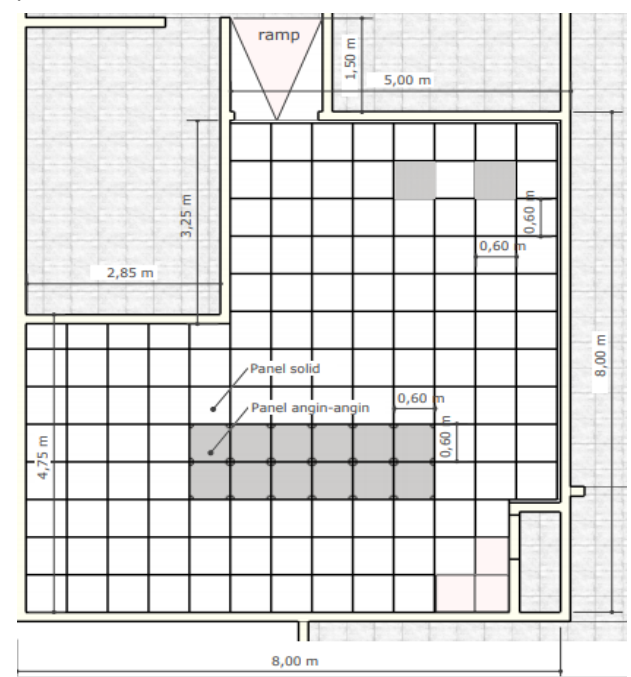

Gambar 2. Denah pemasangan raised floor

\section{Desain Sistem Pendinginan}

Pendinginan yang digunakan pada ruang server menggunakan teknologi HVAC (Heating, Ventilation, Air Conditioning) DX (Direct Expansion) dan tidak menggunakan tambahan sistem heat rejection. Pemilihan alat pendingin ini mengacu pada TIA-942 yang merekomendasikan bahwa penggunaan HVAC DX baik untuk data center kecil karena tidak ada sistem pemipaan air seperti chilled water. Saluran kondensat dan humidifier HVAC harus dirancang dibawah raised floor dan menggunakan saluran berbahan tembaga agar tidak mudah terbakar serta harus dibuat permanen. Mengacu standar AHJ dan HVAC server harus tersedia selama 365 hari pertahun dan 24 jam perhari maka dari itu harus didukung oleh sistem generator siaga. Sistem HVAC merupakan sistem yang baik membentuk pendinginan dan menjaga suhu selalu dalam keadaan rendah dan konstan (Pratama et al., 2020). Adapun keadaan temperatur dan kelembaban yang harus dijaga adalah seperti berikut (MaishaShahrani et al., 2019) :

I) Temperatur kering berkisar dirange $20^{\circ} \mathrm{C}-25^{\circ} \mathrm{C}$ $\left(68^{\circ} \mathrm{F}-77^{\circ} \mathrm{F}\right)$ dengan keadaan temperatur normal diset menjadi $22^{\circ} \mathrm{C} \pm 1^{\circ} \mathrm{C}$.

2) Kelembaban relatif $40 \%$ - $50 \%$ dengan titik normal berada pada $45 \% \pm 5 \%$.

3) Titik embun maksimum $21^{\circ} \mathrm{C}\left(69.8^{\circ} \mathrm{F}\right)$.

4) Perubahan maksimum yang boleh terjadi dari batas suhu sekarang adalah sebesar $5^{\circ} \mathrm{C}\left(9^{\circ} \mathrm{F}\right)$ per jam.

Metode yang digunakan dalam melakukan pendinginan adalah Row Oriented Cooling System. Metode tersebut menerapkan pendinginan dengan membentuk hot and cold aisles. Adapun peralatan pendingin memiliki fitur humidity control dan digabung dengan exhaust fan untuk menghisap udara panas pada hot aisles. Berikut Gambar 3 cara kerja HVAC pada ruangan data center yang diusulakan.

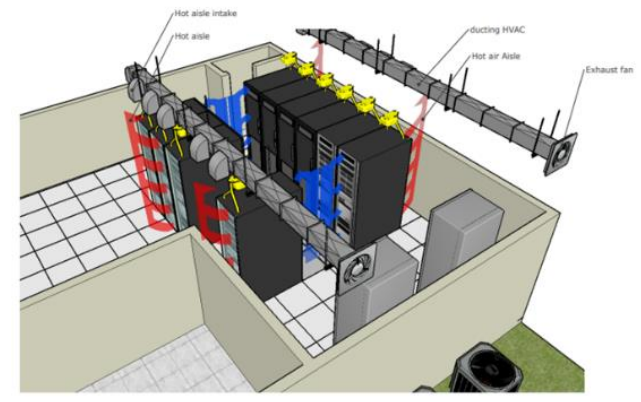

Gambar 3. Cara kerja HVAC

Pada Gambar 3 terjadi pemisahan antara lorong panas dan lorong dingin. Udara panas yang keluar dari bagian belakang server akan dikepung di lorong panas akan ditarik menggunakan fan untuk selanjutnya didistribusikan ke lorong dingin sehingga mengalami proses pendinginan. Udara yang terkepung di dalam lorong dingin akan disalurkan ke perangkat server melalui lubang udara yang terdapat pada rack server (perforated ventilation panel) untuk menghindari adanya overheating.

\section{Desain Sistem Kelistrikan}

Sistem listrik data center mempunyai ruangan tersendiri agar tidak terjadi interferensi dengan peralatan data center yang berada pada ruang control. Ada beberapa unsur yang harus dipenuhi dalam sistem kelistrikan yaitu TVSS (Transient voltage surge suppression), EPO System (Emergency Power Off) dan UPB (UPS panel board). Berikut Gambar 4 panel elektrikal control dan Gambar 5 desain kelistrikan single line diagram. 


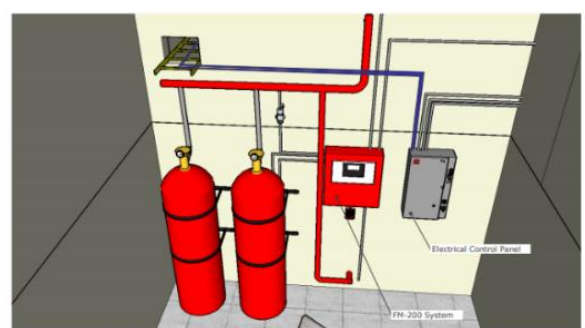

Gambar 4. Panel elektrikal control

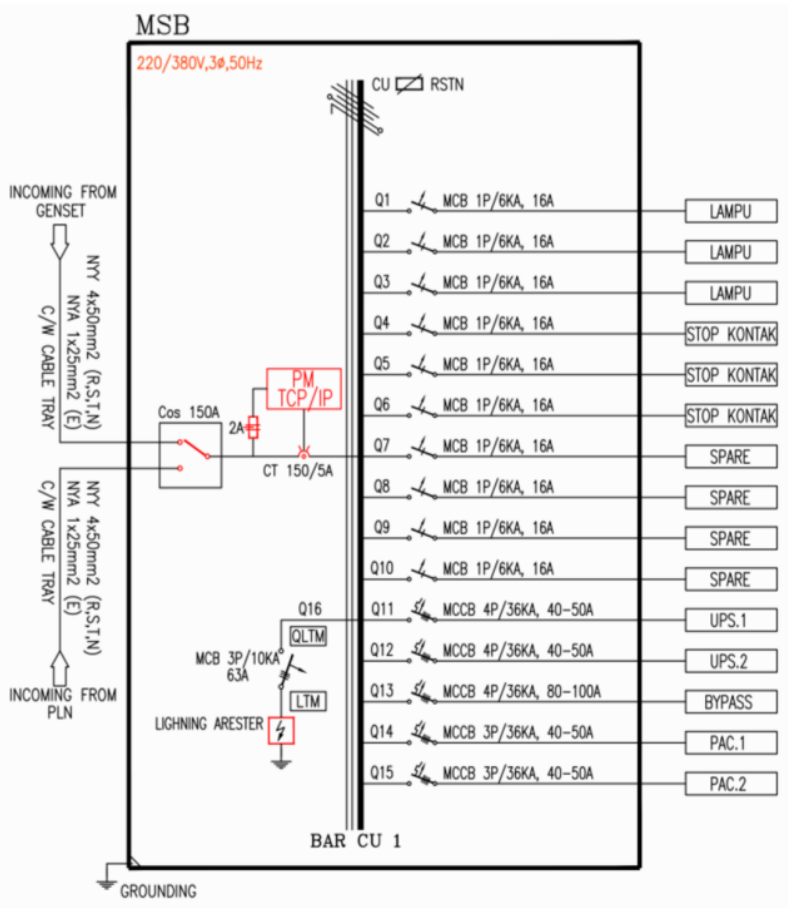

Gambar 5. Desain kelistrikan single line diagram

\section{Sistem Cadangan dan Standby}

Sistem cadangan dan standby merupakan sistem listrik siaga untuk data center yang terdiri dari generator, Uninterruptible Power Supply (UPS), Automatic Transfer Switch (ATS), dan baterai backup.

a) Generator

Generator pada data center harus mampu mengsuplai listrik untuk keseluruhan sistem infrastruktur diruang pendukung dan ruang server. Adapun generator yang akan digunakan adalah yang memenuhi kriteria minimum sebagai berikut :

- Bahan bakar generator harus diesel.

- Ukuran spesifikasi generator harus disesuaikan dengan kapasitas UPS yg terpasang.

- Generator harus dapat memberikan pasokan listrik dalam beban penuh minimal selama 8 jam untuk sistem listrik data center seperti lighting, HVAC system, perangkat ruang pendukung dan computer b) UPS
UPS redundancy pada Tier I adalah N, maksud dari $\mathrm{N}$ yaitu satuan yang merujuk kepada total keseluruhan daya pada beban penuh computer equipment di ruang server (Putra and Aristana, 2019). Topologi yang digunakan untuk data center usulan adalah UPS single module. UPS single module merupakan suatu topologi dimana hanya ada satu UPS dengan daya yang mengcover listrik dalam beban penuh dan UPS yang digunakan adalah UPS dengan static technology atau lebih dikenal dengan static UPS double conversion (Aamir et al., 2016). Berikut Gambar 6 diagram single line pada UPS.

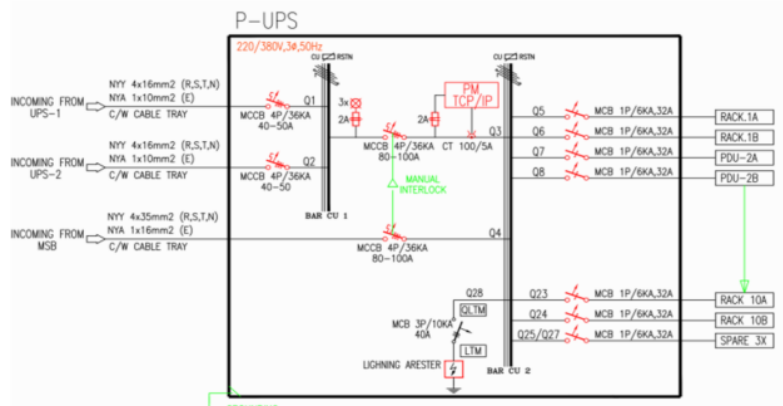

Gambar 6. Panel diagram single line UPS

c) ATS

Penggunaan ATS pada perancangan ini digunakan untuk memindahkan sumber listrik utama secara otomatis kesumber listrik cadangan (Generator). Pemindahan otomatis oleh ATS dilakukan jika terdeteksi sumber listrik utama mati dan juga dapat mengembalikan power listrik seperti semula jika sumber utamanya sudah aktif. Penggunaan ATS sangat dibutuhkan untuk menjaga availability pada data center karena ATS dapat menghidupkan generator secara otomatis tanpa campur tangan manusia.

c) Baterai Backup

Jenis baterai yang digunakan adalah tipe VRLA (valve regulated lead acid). Baterai backup harus bisa memberikan cadangan listrik ke UPS minimal selama 5 menit. Sakelar listrik untuk baterai backup harus disediakan serta dilokasikan diluar ruang mekanik. Pemasangan menggunakan rangkaian baterai biasa pada semua modul.

\section{Desain Struktur Kabel}

Perancangan struktur kabel harus mengetahui topologi pengkabelan data center terlebih dahulu, topologi yang dipakai untuk data center adalah reduced data center topology (Association Telecommunications Industry, 2012), berikut Gambar 7 topologi reduced data center. 


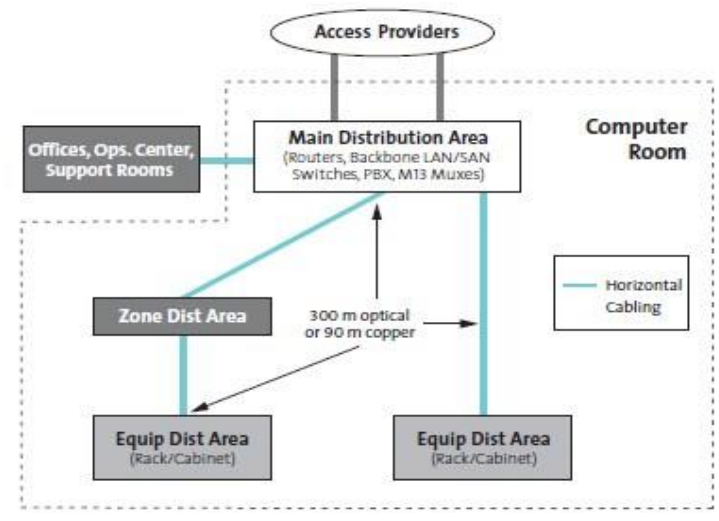

Gambar 7. Topologi reduced data center.

Pada Gambar 7 pemilihan topologi bedasar kebutuhan data center kecil karena main cross-connect dan horizontal cross-connect dapat digabung pada main distribution area (mda). Adapun Pada sistem pengkabelan data center menggunakan denah seperti Gambar 8.

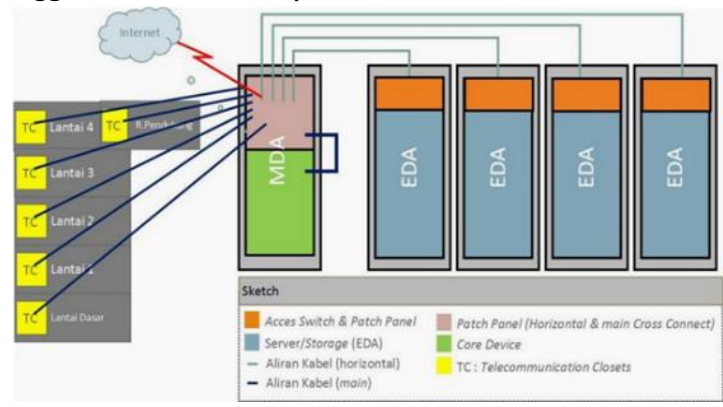

Gambar 8. Denah struktur pengkabelan

Dari Gambar 8, terlihat bawah aliran pengkabelan data center berawal dari mda, pada mda terdapat core device yang berisi router mikrotik, cyberoam firewall dan switch layer 3. Switch layer 3 digunakan untuk distribusi internet ke telecommunication closets melalui patch panel atau lebih dikenal dengan nama main cross-connect dan didistribusikan ke server-server dalam kabinet dan office.

\section{Desain Rack dan Kabinet}

Kabinet yang digunakan adalah yang memenuhi kriteria sebagai berikut :

a) Ukuran tinggi tidak lebih dari $2,40 \mathrm{~m}$, lebar $0,60 \mathrm{~m}$ dan kedalaman I, $10 \mathrm{~m}$.

b) Rel bagian depan atau belakang tersembunyi minimal $100 \mathrm{~mm}$.

c) Berukuran minimal $42 R U$.

d) Memiliki ventilasi yang cukup untuk peralatan didalamnya

e) Memiliki fitur sistem grounding dan vertical cable manager. Setiap kabinet yang terpasang harus memiliki area untuk pengaksesan atau disebut dengan clearance area. Adapun clearance area yang akan diterapkan untuk bagian belakang kabinet adalah 0,60 $\mathrm{m}$ dan untuk bagian depan kabinet I,00 m. Dalam penempatan kabinet pada raised floor, kabinet harus dikuatkan dengan baut mur untuk mencegah terjadinya guncangan serta bagian depan kabinet harus menyesuaikan dengan baris cold aisles agar peralatan didalam kabinet dapat menghisap udara dingin yang keluar dari perforated tiles dan tidak mengganggu dalam pengangkatan ubin depan dan belakang dari kabinet.

a) Dalam kabinet menyediakan power strip berkapasitas 20A, I20V serta menyediakan kapasitas colokan yang memadai. Power strip yang akan digunakan adalah merek APC type ap7830 vertical, mempunyai fitur monitoring pemakaian daya hingga per outlet, mempunyai alarm, pengendali outlet jarak jauh (remote via internet) dan memiliki proteksi circuit breaker.

Berikut Gambar 9 desain susunan perangkat kabinet dan Gambar 10 denah perencanaan posisi cabinet.

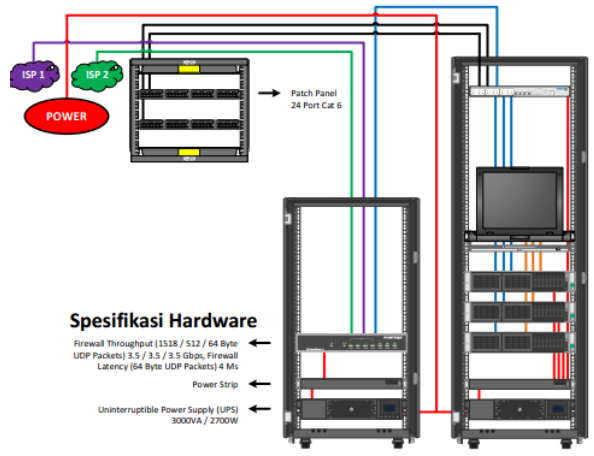

Gambar 9. Desain susunan perangkat kabinet

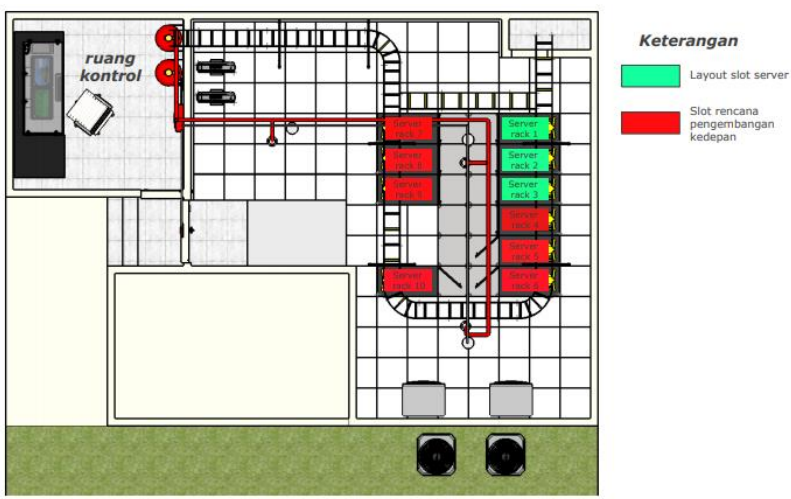

Gambar 10. Denah perencanaan posisi kabinet

\section{Desain Cable Tray Listrik dan Data}

Cable tray pada data center difungsikan untuk kabel listrik dan data. cable tray listrik terletak dibawah raised floor atau dikenal dengan cable tray under floor dan harus dikuatkan sesuai dengan aturan pemasangan yang berlaku, sedangkan cable tray data berada di atas langitlangit ruang server (Elfanuary et al., 2017). Cable tray yang digunakan adalah jenis wire basket berbahan 
Abdul Hadi, Herkules \& Norhayati. Perencanaan Layout Data Center Dinas Komunikasí

Informatika Persandian dan Statistik Provinsi Kalimantan Tengah

alumunium yang memilki dimensi lebar dan tinggi adalah $20 \times 10 \mathrm{~cm}$. Berikut Gambar II desain cable tray listrik dan Gambar 12 desain cable tray data.

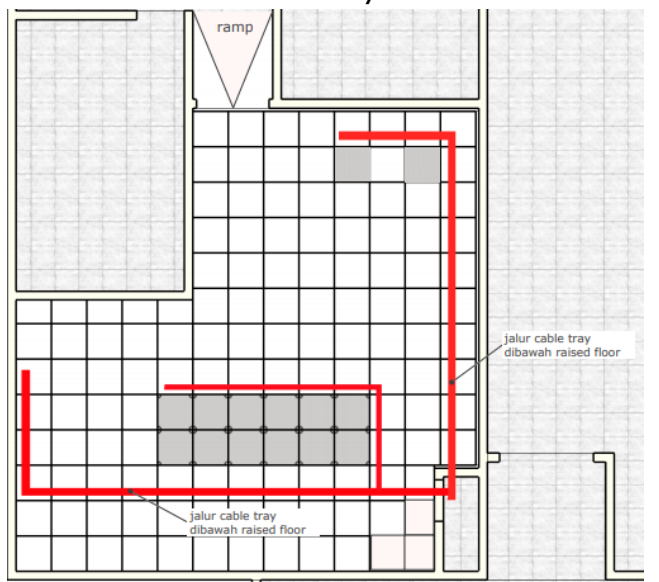

Gambar II. Desain cable tray listrik dibawah raised floor

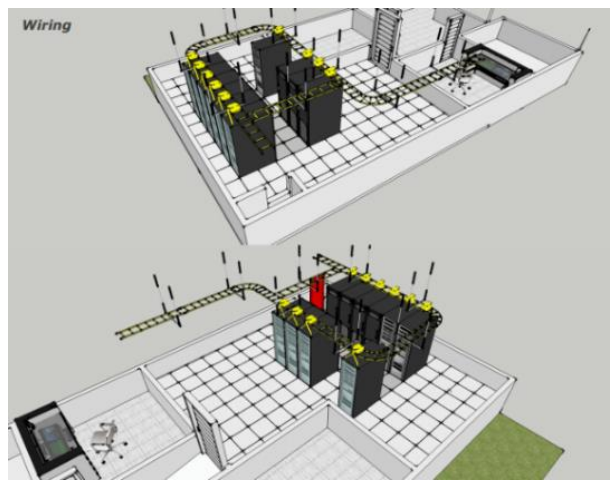

Gambar 12. Desain kabel data terpasang diatas langitlangit

\section{Desain proteksi kebakaran}

Peralatan proteksi kebakaran pada data centre menggunakan gaseous suppression yang tidak merusak elektrikal pada ruangan server. Berikut Gambar 13 denah sistem fire suppression.

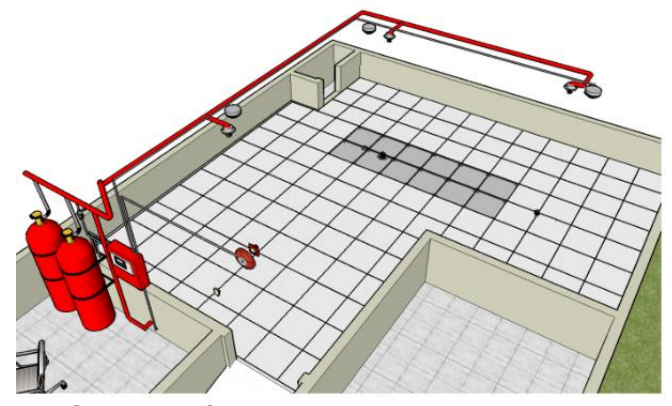

Gambar 13. Denah struktur pengkabelan

Pada Gambar 13 terlihat bahwa peletakan nozzle dan sensor berada pada ruangan server. Pada ruangan server terdapat enam pemasangan nozzle beserta sensor detectornya yang terbagi menjadi dua bagian yaitu terletak di under floor dan over head. Pada over head pemasangan dilakukan pada hot aisles dan dekat HVAC. Sedangkan under floor diletakan pada jalur tray kabel data yang banyak penyambungan kabelnya yaitu mda dan didekat panel circuit. Cara kerja sistem ini adalah jika sensor mendeteksi asap maka akan memberikan sinyal ke fenwall control unit dan dari fenwall control unit menugaskan gas fm-200 untuk dikeluarkan melalui nozzle yang berdekatan dengan sensor yang mendeteksi asap tersebut.

\section{Desain Sistem Monitoring Lingkungan}

Sistem monitoring lingkungan atau bisa disebut Environment Monitoring System (EMS) berfungsi untuk pemantauan perangkat berdasar suhu, kelembaban dan memberikan alarm apabila terjadi kerusakan atau terjadi bencana. Setiap perangkat pada ruang server akan dimonitor, apabila terjadi gangguan sistem EMS akan memberikan peringatan di ruang monitoring. Berikut Gambar 14 diagram pengkabelan EMS.

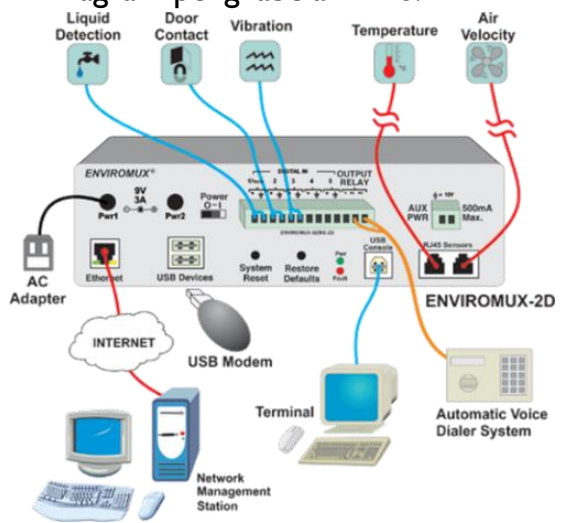

Gambar 14. Diagram Pengkabelan EMS

(Sumber : www.infinialogic.com)

\section{Desain Sistem Pengamanan}

Perancangan sistem keamanan data center harus memenuhi aspek availbility, confidentiality dan integrity (Bima Priatmoko Endang Siti Astuti Riyadi, 2016). Komponen-komponen pengaman minimal standart TIA942 secara fisik seperti closed-circuit television (CCTV) dan access door terpasang di ruang server (Verma and Tripathi, 2010). Penggunaan CCTV sebanyak dua unit yang terletak pada pojok atas ruangan sedangkan access door hanya digunakan untuk ruang server. Ukuran tinggi dan lebar pintu masuk data center serta ruang server adalah 2,13 × 1,20 meter bahan besi seperti pada Gambar 15. 


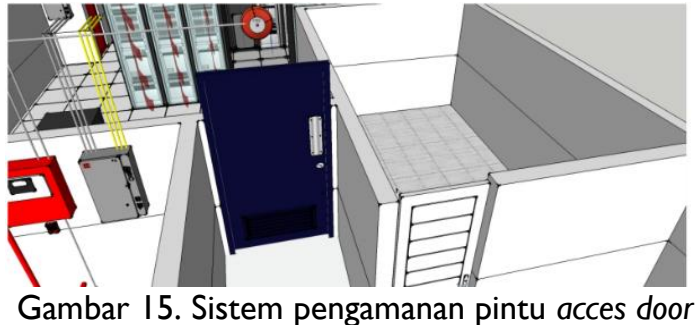

\section{Simpulan Dan Saran}

Perancangan dan implementasi data center harus memenuhi standar tertentu untuk menjamin aspek ketersediaan (availbility), privasi (confidentiality), dan keutuhan (integrity) data yang disimpan. Penyusunan perencanaan perangkat data center Diskominfo Prov. Kalteng dilakukan dengan menggunakan Standarisasi TIA-942, yakni pendekatan perencanaan data center tier I Basic. Konsep desain data center dianalisis berdasar kebutuhan perangkat keras dan lunak dan diuraikan ke dalam beberapa proses yaitu penentuan lokasi, desain raised floor, desain pendinginan, desain kelistrikan, desain sturktur kabel, desain proteksi, desain monitoring, dan desain pengamanan.

Adapan saran dan harapan yang diberikan penulis untuk penelitian selanjutnya adalah perhitungan kebutuhan biaya dan membuat perencanaan perangkat data center dengan pendekatan standarisasi TIA-942 Tier II agar tingkat down time tolerant lebih kecil dari 28,8 jam/tahun.

\section{Daftar Pustaka}

Aamir, M., Ahmed Kalwar, K., Mekhilef, S., 2016. Review: Uninterruptible Power Supply (UPS) system. Renew. Sustain. Energy Rev. 58, I395-1410. https://doi.org/https://doi.org//0.1016/j.rser.2015.I 2.335

Association Telecommunications Industry, 2012. Tia Standard I-I48.

Bima Priatmoko Endang Siti Astuti Riyadi, D., 2016. Analisis Penerapan Sistem Keamanan Fisik Pada Data Center Untuk Melindungi Data Organisasi (Studi Kasus Pada Unit Penerimaan Mahasiswa Baru Dan Sistem Informasi (PMBSI) IKIP PGRI MADIUN). J. Adm. Bisnis (JAB)|Vol 40, I60-169.

Dewandaru, D.S., Bachtiar, A., 20I4. Perancangan Desain Ruangan Data Center Menggunakan Standar Tia942 (Studi Kasus: Puslitbang Jalan Dan Jembatan). Semin. Nas. Sist. Inf. Indones. 3, 44I-448.

Diminico, C., 2004. Standard for Data Centers. Distribution 4I, 36.

Elfanuary, F., Rohmat, R., Hediyanto, U.Y.K.S., 20I7. Dan Data Center Layout Berdasarkan Tiering Level Standar Tia-942 Dengan Metode Ppdioo Di Pemerintah Kabupaten Bandung Best Practice Design Building Facilities and Data Center Layout Based on Tiering Level of Tia-942 Standard Using Ppdioo Method in 4, 205-216.
Ismail, A., Ridwan, M., 2018. Desain Data Center Berbasis Hyper Converged Infrastructure Dengan Standar Tia-942 Untuk Green Campus. J. Penelit. Dan Karya IIm. 18, I-14. https://doi.org//0.33592/pelita.v|8il.27

MaishaShahrani, T., Ramdhania, A.N., Lubis, M., 2019. Implementation of Building Construction and Environment Control for Data Centre Based on ANSI/TIA-942 in Networking Content Company. J. Phys. Conf. Ser. 1361. https://doi.org//0.1088//742-6596//36I///0I 2074

Pratama, Y.S., Budiono, A., Almaarif, A., 2020. Analisis Dan Perancangan Cooling Management Data Center Berdasarkan Standar Tia-942 Menggunakan Ppdioo Life-Cycle Approach Di Pemerintahan Kabupaten Bandung Barat Analysis And Designing Of Cooling Management Data Center Based On Tia-942 Standards Using PP 7, 6656-6663.

Putra, I.D.P.G.W., Aristana, M.D.W., 2019. Perancangan Desain Ruangan Data Center Menggunakan Standar Tia-942. J. Resist. (Rekayasa Sist. Komputer) 2, I-5. https://doi.org/I0.3 I598/jurnalresistor.v2il .370

Rasmussen, N., 2014. Raised Floors vs Hard Floors for Data Center Applications Executive summary Raised Floors vs Hard Floors for Data Center Applications.

Verma, G.K., Tripathi, P., 20I0. A Digital Security System with Door Lock System Using RFID Technology. Int. J. Comput. Appl. 5, 6-8. https://doi.org/I0.5 I20/957-I334 